\title{
Dare to double spare?
}

\author{
Tomasz A. Timek, MD, PhD
}

\author{
From the Division of Cardiothoracic Surgery, Spectrum Health, Grand Rapids, Mich. \\ Disclosures: Author has nothing to disclose with regard to commercial support. \\ Received for publication Feb 3, 2017; accepted for publication Feb 10, 2017; available ahead of print March 8 , \\ 2017. \\ Address for reprints: Tomasz A. Timek, MD, PhD, Division of Cardiothoracic Surgery, Spectrum Health, 100 \\ Michigan Ave NE, Grand Rapids, MI 49503 (E-mail: tomasz.timek@spectrumhealth.org). \\ J Thorac Cardiovasc Surg 2017;153:1031-2 \\ $0022-5223 / \$ 36.00$ \\ Copyright (C) 2017 by The American Association for Thoracic Surgery \\ http://dx.doi.org/10.1016/j.jtcvs.2017.02.021
}

Valve preservation surgery has been firmly established as optimal surgical treatment for degenerative mitral valve disease and is emerging as the procedure of choice for certain forms of aortic root pathology. ${ }^{1}$ In the current issue of the Journal, Javadilasgari and colleagues ${ }^{2}$ from the Cleveland Clinic present a series of 118 patients with both aortic root and mitral valve pathology of whom 41 had combined aortic and mitral valve-sparing operations. The authors should be congratulated for pushing the limits of valve preservation, and the low reoperative rate of $7.8 \%$ at 10 years speaks to the validity of their approach. Mitral repair rate of $86 \%$ in light of a significant number of patients requiring anterior leaflet procedures is impressive as is the overall $1.4 \%$ perioperative mortality for these complex operations. The surgical expertise required to execute these operations calls for an "aortic surgeon" to collaborate with a "mitral surgeon" as described by the authors, and such cooperation in centers of excellence will undoubtedly provide optimal outcomes for these challenging patients. The novel concept of a cardiac surgeon team challenges traditional barriers and is in itself noteworthy and deserves attention. On many levels, the study challenges the cardiac community to join the quest that the authors embarked on several years ago.

The extrapolation of the presented surgical strategy may, however, be difficult in a "real-world" scenario. The cohort of 41 combined valve-sparing operations over almost 30 years at a center currently performing more than 4000 cardiac operations annually represents a highly unusual and selected patient population that is unlikely to be duplicated in but a few centers around the world. Currently, only 5\% of cardiac centers in the United States perform more than 16 aortic root surgeries per year, ${ }^{3}$ and rate of mitral valve repair nationally is still suboptimal. ${ }^{4}$ The call to perform such specialized procedures in high-volume centers ${ }^{5}$ should therefore be heeded. The authors demonstrated that double valve-sparing operations were associated with very good survival, but the follow-up was limited with only 15 patients at risk at 5 years and 8 at risk at 10 years. On the same note,

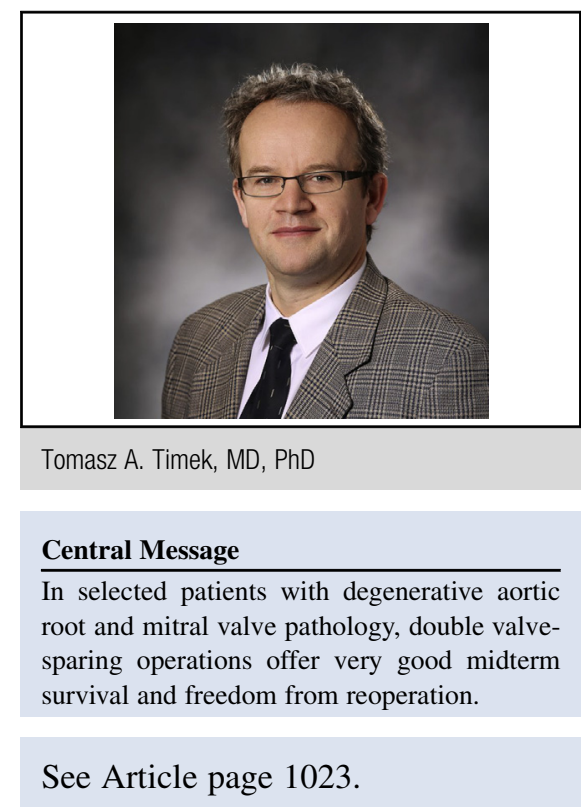

freedom from reoperation was impressive, but echo follow-up was not available, and therefore it is unknown what proportions of these patients may be surviving with significant single or double valve insufficiency. As such, the authors have illustrated the feasibility of a double valve-sparing procedure, but durability, in large part, remains to be determined. On the other hand, the results of a combined Bentall and mitral valve operation at 10 years were quite satisfactory, with $73.0 \%$ survival rate and $9.8 \%$ reoperation risk. For most surgeons in busy clinical practice, this approach is familiar and feasible. The competing risk of reoperation also should be evaluated in the context of now readily available transcatheter technologies that provide novel solutions. Transcatheter aortic valve replacement for prosthetic aortic valve degeneration is becoming a clinical reality and mitral options are on the horizon. ${ }^{6} \mathrm{~A}$ degenerated bioBentall could be addressed with a valve-in-valve transcatheter aortic valve replacement, but a failing valvesparing aortic operation would, under current indications, require surgical intervention.

The feasibility of a combined aortic and mitral valvesparing operation for very select patients has been demonstrated by the Cleveland Clinic group, and the collaboration of subspecialty experts to provide this surgical therapy should be applauded. As clinical experience grows and long-term follow-up data become available, double valve-sparing operations may gain further clinical foothold, but at present, caution should be exercised 
when contemplating these complex surgeries and alternatives considered.

\section{References}

1. Ouzounian M, Rao V, Manlhiot C, Abraham N, David C, Feindel CM, et al. Valvesparing root replacement compared with composite valve graft procedures in patients with aortic root dilation. J Am Coll Cardiol. 2016;68:1838-47.

2. Javadilasgari H, Roselli EE, Aftab M, Suri RM, Desai MY, Khosravi M, et al. Combined aortic root and mitral valve surgery: the quest to preserve both valves. J Thorac Cardiovasc Surg. 2017;153:1023-30.e1.
3. Stamou SC, Williams ML, Gunn TM, Hagberg RC, Lobdell KW, Kouchoukos NT. Aortic root surgery in the United States: a report from the Society of Thoracic Surgeons database. J Thorac Cardiovasc Surg. 2015;149:116-22.

4. Gammie JS, Sheng S, Griffith BP, Peterson ED, Rankin JS, O'Brien SM, et al. Trends in mitral valve surgery in the United States: results from the Society of Thoracic Surgeons Adult Cardiac Surgery Database. Ann Thorac Surg. 2009;87: 1431-7.

5. Miller DC. Aortic valve-sparing surgery: yes, but not for every patient and select the center very carefully. J Am Coll Cardiol. 2016;68:1848-50.

6. Ye J, Cheung A, Yamashita M, Wood D, Peng D, Gao M, et al. Transcatheter aortic and mitral valve-in-valve implantation for failed surgical bioprosthetic valves. JACC Cardiovasc Interv. 2015;8:1735-44. 